\title{
B16 Investigação dos mecanismos moleculares pelos quais o PCA3 modula a sobrevivência de células de câncer de próstata
}

Ana Emília Goulart ${ }^{1}$, Luciana Bueno Ferreira², Nadia Maria Batoreu ${ }^{3}$, Martin Hernan Bonamino ${ }^{4}$, Etel Rodrigues Pereira Gimba ${ }^{5}$

${ }^{1}$ LATER, Programa de Biofármacos e Instituto Nacional de Câncer, Centro de Pesquisa, Programa de Carcinogênese Molecular, BioManguinhos, Fundação Oswaldo Cruz, Rio de Janeiro, RJ

2 IPATIMUP, Universidade do Porto, Portugal,

3 Programa de Biofármacos, Bio-Manguinhos, Fundação Oswaldo Cruz, Rio de Janeiro, RJ

${ }^{4}$ Instituto Nacional de Câncer, Centro de Pesquisa, Programa de Carcinogênese Molecular

${ }^{5}$ Instituto Nacional de Câncer, Centro de Pesquisa, Programa de Carcinogênese Molecular e Universidade Federal Fluminense, IHS, Departamento Interdisciplinar

Introdução: O RNA não codificante (ncRNA) PCA3 está envolvido no controle da sobrevivência de células de câncer de próstata $(\mathrm{CaP})$, através da modulação da via de sinalização do receptor de androgênio (AR).

Objetivo: Para melhor caracterizar por quais mecanismos moleculares - PCA3 controla a sobrevivência das células LNCaP, objetivamos investigar se os diversos genes relacionados ao câncer - incluindo os envolvidos na transição epitelial mesenquimal (EMT), os que apresentam potencial stemness e os co-reguladores da via do AR podem estar envolvidos no processo de resposta à inibição do PCA3.

Metodologia: Empregamos small interfering RNA (siRNA) ou short hairpin RNA (shRNA) com expressão baseada em vetores lentivirais para inibir a expressão de PCA3 e avaliar os efeitos deste silenciamento na sobrevivência de células LNCaP. Após a interferência do PCA3, analisamos por RT-PCR a expressão de marcadores EMT, co-reguladores do AR, genes com potencial stemness e diversos genes relacionados ao câncer; utilizamos microscopia confocal para analisar a expressão da vimentina; empregamos citometria de fluxo para verificar o percentual de células

LNCaP GFP+, após a transdução com vetores lentivirais.

Resultados: Dentre 84 genes relacionados ao câncer, 16 apresentaram expressão alterada nas células LNCaP interferidas com siPCA3 em relação ao controle de células LNCaP interferidas com siScrbl. Desses, $30 \%$ codificam moléculas de transdução de sinais e/ ou fatores de transcrição. Observou-se expressão aumentada de Ecaderina, Claudina-3, Citoqueratina-18, Snail, Twist e Slug em células LNCaP transfectadas com siPCA3 em relação ao controle, enquanto observou-se expressão diminuída de Claudina-4, Citoqueratina-8 e 
Vimentina. O padrão de marcação de vimentina foi similar em células LNCaP - siPCA3 e células LNCaP - siScrbl. Dentre os coreguladores, ARA 70, ARA 54, Smad3 e EBP1 apresentaram expressão aumentada em células LNCaP- siPCA3 em relação ao controle, enquanto Smad 4 e ciclina D1 apresentaram expressão diminuída. Não foi detectada a expressão de genes com potencial stemness nas condições testadas. Células transduzidas com vetores lentivirais carreando shPCA3 apresentaram diminuição estável da expressão do PCA3. Foi observada redução estável de cerca de $60 \%$ de células LNCaPGFP+transduzidas com shPCA3 em relação aos controles. O mesmo foi observado em experimentos empregando siPCA3.

Conclusão: O silenciamento do PCA3 por RNAi permite diminuição de viabilidade e envolve moléculas-chaves de transdução de sinais e fatores de transcrição que podem orquestrar a sobrevivência de células de $\mathrm{CaP}$. A diminuição na viabilidade das células transfectadas com siPCA3 não é modulada de forma clássica pelo programa EMT, embora alguns marcadores da transição possam regular a morte celular induzida por siPCA3. A desregulação da expressão de coreguladores observada pode modular negativamente a expressão dos genes alvo do AR. A redução estável da expressão de PCA3 mostra o potencial deste ncRNA como ferramenta terapêutica contra o $\mathrm{CaP}$, por sua modulação negativa da sobrevivência celular.

Palavras-Chave: Câncer de Próstata, PCA3 